\title{
PENGARUH MOTIVASI INSTRINSIK, MOTIVASI EKSTRINSIK DAN LINGKUNGAN KERJA TERHADAP KINERJA PEGAWAI KANTOR POS PALANGKARAYA
}

\author{
Tania Desfira Putri Rosyana ${ }^{1}$, Rita Yuanita Toendan ${ }^{2}$, Peridawaty $^{3}$ \\ ${ }^{1,2,3}$ Fakultas Ekonomi dan Bisnis, Universitas Palangka Raya \\ *Corresponding : taniadesfira@gmail.com
}

CHRONICLE
Article History:
Received December 2, 2020
Accepted May 18, 2021

Keywords :

Instrinsic Motivation,

Extrinsic Motivation,

Work Environment and

Employee performance
ABSTRACT
The Influence of Instrinsic Motivation, Extrinsic Motivation and Work Environment on Employee Performance of Palangka Raya Post Office. This study aims to determine the effect of Instrinsic Motivation, Extrinsic Motivation and the Work Environment on Employee Performance of the Palangka Raya Post Office. The research method used an explanatory approach with survey techniques, the number of samples in this study were 45 respondents, the sampling technique used the Census technique. Data collection methods used interview techniques, observation, questionnaires, and documentation studies, while the data analysis techniques used in this study were using descriptive analysis techniques and multiple linear analysis techniques.The results showed that Instrinsic Motivation, Extrinsic Motivation and Work Environment had a significant effect on Employee Performance Performance at Palangka Raya Post Office. And the results of the descriptive analysis state that the respondents agree with the indicators proposed.

\section{Latar Belakang :}

Perusahaan pada saat ini sering menghadapi berbagai persaingan di dalam dunia bisnis yang semakin maju. Oleh karena itu perusahaan harus dibangun dengan sungguh-sungguh agar dapat menghasilkan karyawan yang berkualitas sehingga mampu bersaing dengan perusahaan lain. Lingkungan yang dihadapi oleh manajemen sumber daya manusia sangat menantang karena perubahan muncul sangat cepat dan memiliki masalah yang sangat luas (Mathis, 2009).

Sumber daya manusia adalah aset penting dalam sebuah organisasi, karena sumber daya manusia mempengaruhi efektifitas dan efisiensi organisasi. Peran organisasi tergantung dari kinerja orang-orang yang berada di dalam organisasi. Manusia selalu berperan aktif dalam setiap organisasi, karena manusia menjadi perencana, pelaku, penentu dan pengambil keputusan untuk mewujudkan, tujuan organisasi.

Upaya untuk membentuk terciptanya seorang karyawan yang mempunyai kinerja yang baik tentunya merupakan suatu tantangan bagi setiap organisasi termasuk Kantor Pos Palangka Raya. Motivasi adalah hal penting karena motivasi mendukung perilaku manusia supaya mau bekerja giat dan antusias dalam mencapai hal yang optimal. Motivasi sebagai dorongan, merupakan faktor penting dalam menjalankan pekerjaan secara optimal. Tanpa adanya motivasi, seorang karyawan akan merasa segan untuk melaksanakan suatu pekerjaan, dengan baik. Kinerja karyawan akan tercapai apabila karyawan itu sendiri mempunyai motivasi kerja yang tinggi. Motivasi kerja akan dicapai bila ada kemauan dari diri sendiri dan mendapat 
dorongan dari pihak lain.

Hasibuan (2016) menyatakan tingkah laku seseorang dipengaruhi secara dirangsang oleh keinginan, kebutuhan, tujuan dan kepuasannya. Rangsangan ini timbul dari diri sendiri (intrinsik) dan dari luar (ekstrinsik) atau lingkungan. Rangsangan yang berbentuk materil akan menciptakan "motif dan motivasi" yang mendorong orang beraktifitas untuk memperoleh kebutuhan dan kepuasan dari hasil kinerjanya. Melihat pentingnya motivasi kerja dan lingkungan kerja dalam meningkatkan kinerja pegawai, maka Kantor Pos Palangka Raya seharusnya memberikan motivasi kerjakepada pegawai, memberikan lingkungan kerja yang nyaman sehingga peningkatan kinerja dapat tercapai.

Pemasalahan yang terjadi adalah pegawai merasa kurangnya pengakuan pimpinaan atas hasil kerja yang telah dicapai pegawainya . Pengakuan adalah suatu bentuk umpan balik atas hasil kerja yang telah diraih. Pengakuan tidak hanya bertujuan untuk menghargai kinerja pegawai, tetapi juga untuk motivasi pegawai untuk lebih meningkatkan kinerjanya. Advacement (pengembangan), Kurangnya kesempatan promosi yang diberikan pimpinan terhadap pegawainya nya. Selain menghargai kinerja bagus dari pegawai, promosi juga bertujuan mengembangkan keterampilan pegawai serta kurangnya sarana prasarana yang ada di kantor, lingkungan kantor yang belum tertata dengan baik seperti penempatan alat-alat kantor sembarangan, arsip kantor yang hanya disimpan di dalam kardus dan diluar lemari penyimpanan, lorong toilet dijadikan gudang,serta cat dinding yang berlumut.

Berdasarkan latar belakang permasalahan tersebut di atas, maka peneliti tertarik untuk mengkaji lebih dalam dapat memberikan manfaat baik secara teoritis maupun praktis kepada berbagai pihak yaitu: dapat memberikan sumbangan teoritis dan pengembangan konsep manajemen sumber daya manusia, khususnya yang berhubungan dengan Motivasi Intrinsik, Motivasi Ekstrinsik dan Lingkungan Kerja terhadap kinerja Pegawai Kantor Pos Palangka Raya. Dapat digunakan sebagai referensi dan sumber informasi untuk penelitian selanjutnya dalam bidang sumber daya manusia.

\section{Tinjauan Pustaka}

\subsection{Motivasi}

Motivasi merupakan faktor-faktor yang menyebabkan, menyalurkan dan menopang perilaku individu/anggota-anggota organisasi. Istilah motivasi (motivation) berasal dari perkataan bahasa latin yakni "Movere", yang berarti "menggerakkan" (To Move). Oleh karena itu, secara etimologis motivasi berkaitan dengan alasan-alasan atau hal-hal yang telah mendorong atau menggerakkan seseorang untuk melakukan sesuatu (Winardi, 2001).

Dikalangan para teoritikus dan praktisi manajemen telah lama diketahui bahwa masalah motivasi bukanlah masalah yang mudah, baik memahaminya apalagi menerapkannya. Akan tetapi yang jelas ialah bahwa dengan motivasi yang tepat para karyawan akan terdorong untuk berbuat semaksimal mungkin dalam pelaksanaan tugasnya karena meyakini dengan keberhasilan organisasi mencapai tujuan dan berbagai sasarannya, kepentingan-kepentingan pribadi para anggota organisasi tersebut akan terpelihara pula.

Hal yang mungkin lebih penting, dibandingkan dengan pilihan tentang sebuah definisi khusus tentang motivasi adalah pandangan motivasi memiliki sejumlah sifat yang mendasarinya. Adapun sifat-sifat tersebut Mitchell (dalam Winardi, 2001 ) mengemukakan :

- Ia merupakan sebuah fenomin individual masing-masing individu bersifat unik, dan fakta tersebut harus diingat pada riset motivasi.

- Motivasi bersifat internasional apabila seseorang karyawan melaksanakan suatu tindakan, maka hal tersebut, disebabkan karena orang tersebut secara sadar, telah memilih tindakan tersebut.

- Motivasi memiliki macam-macam faset para periset telah menganalisis berbagai macam aspek motivasi, dan termasuk didalamnya bagaimana motivasi tersebut ditimbulkan, 
bagaimana dia diarahkan, dan pengaruh apa menyebabkan timbulnya persistensinya, dan bagaimana motivasi dihentikan.

- Tujuan teori motivasi adalah : memprediksi perilaku - perlu ditekankan perbedaanperbedaan antara motivasi, perilaku dan kinerja (performa). Motivasi penyebab perilaku; andaikata perilaku tersebut efektif, maka akibatnya berupa kinerja tinggi.

\subsection{Lingkungan Kerja}

Lingkungan kerja adalah konsep yang luas karena menyangkut apa yang dilihat, didengar dan dirasakan oleh pegawai baik berupa benda, orang, situasi dan kondisi dan apa yang ada di sekitar tempat kerja, dan kesemuanya berpengaruh terhadap pelaksanaan tugas atau pekerjaan pegawai. Konsep lingkungan kerja itu sendiri bermakna suatu keadaan yang kondusif, nyaman dan aman. Kondusif artinya suasana lingkungan kerja baik orang dan benda cukup mendukung, nyaman menyangkut kebersihan, keindahan, kesejukan, bahkan penerbangan dan pewarnaan, sedangkan aman menyangkut kesehatan dan keselamatan kerja.

Lingkungan kerja didalam suatu perusahaan sangat penting untuk diperhatikan oleh manajemen perusahaan. Walaupun lingkungan kerja ini tidak berfungsi sebagai mesin dan peralatan produksi yang langsung memproses bahan jadi produk, namun berpengaruh dari lingkungan kerja ini akan terasa didalam proses produksi yang dilaksanakan perusahaan, lingkungan kerja ini akan mempunyai pengaruh langsung terhadap para karyawan, lingkungan kerja yang sangat tidak memuaskan akan dapat mengurangi gairah kerja dan menurunkan tingkat produktivitas kerja para karyawan. Hubungan antara lingkungan kerja yang baik dengan tingginya tingkat produktivitas kerja para karyawan didalam perusahaan memang tidak perlu diragukan lagi.

\subsection{Pengertian Kinerja}

Ada banyak pendapat mengenai pengertian kinerja (performance), namun pada prinsipnya adalah sama yaitu hasil dari pekerjaan yang telah dilakukan seseorang. Kinerja sering dijadikan ukuran prestasi kerja, artinya jika kinerja seseorang baik maka dapat dikatakan orang tersebut berprestasi, atau sebaliknya jika prestasi kerja seseorang baik maka dapat dikatakan berkinerja tinggi. Menurut Suyadi (2010), "kinerja atau performance adalah hasil kerja yang dapat dicapai oleh seseorang atau sekelompok orang dalam suatu organisasi, sesuai dengan wewenang dan tanggung jawab. Menurut Armstrong dan Baron (dalam Wibowo (2007), diartikan sebagai hasil kerja atau prestasi kerja. Kinerja adalah tentang melakukan pekerjaan dan hasil yang dicapai dari pekerjaan tersebut. Kinerja adalah tentang apa yang dikerjakan dan bagaimana cara mengerjakannya. Kinerja merupakan hasil pekerjaan yang mempunyai hubungan kuat dengan tujuan strategis organisasi, kepuasan konsumen dan memberikan kontribusi ekonomi. Menurut Wibowo (2007), kinerja adalah merupakan implementasi dari rencana yang disusun tersebut. Implementasi kinerja dilakukan oleh sumber daya manusia yang memiliki kemampuan, kompetensi, motivasi, dan kepentingan. Sedangkan kinerja organisasi ditunjukan oleh bagaimana proses berlangsungnya kegiatan untuk mencapai tujuan tersebut. Evaluasi kinerja dilakukan terhadap hasil kerja individu dalam organisasi. Keberhasilan kinerja individu sangat berpengaruh terhadap hasil kerja organisasi.

Menurut Stoner (dalam Swasto, 1996); bahwa kinerja merupakan ukuran dari prestasi kerja, yaitu kualitas dan kuantitas pekerjaan yang diselesaikan individu, kelompok atau organisasi. Hal ini berarti bahwa kinerja terdiri dari :

a. Komponen kualitas,

b. Kuantitas dan

c. Efektivitas,

Mitchell, 1978 (dalam Suyadi, 2010), menyatakan pula bahwa kinerja meliputi beberapa aspek, yaitu: 
a. Quality of work, yaitu kualitas hasil pekerjaan

b. Promptness, yaitu ketepatan waktu

c. Initiative, yaitu inisiatif atau prakarsa

d. Capability, yaitu kemampuan

e. Communication, yaitu komunikasi.

Kelima aspek tersebut dapat dijadikan ukuran dalam mengadakan pengkajian tingkat kinerja seseorang. Disamping itu Mitchell, 1978 (dalam Sedarmanti, 2001) bahwa untuk mengadakan pengukuran terhadap kinerja, ditetapkan:

$$
\text { Performance }=\text { Ability } x \text { Motivation }
$$

Menurut Mathis et.al (2006), kinerja adalah "apa yang dilakukan atau tidak dilakukan oleh karyawan".

Kemampuan (Ability-A) x Usaha (Effort-E) x Dukungan (Support-S)

Dapat disimpulkan bahwa kinerja merupakan ukuran prestasi kerja. Sedangkan prestasi kerja menurut Hasibuan (2016); adalah sesuatu hasil kerja yang dicapai seseorang dalam melaksanakan tugas-tugas yang dibebankan kepadanya yang didasarkan atas kecakapan, pengalaman, dan kesungguhan serta waktu. Prestasi kerja merupakan gabungan dari tiga faktor penting, yaitu : 1). Minat seorang pekerja, 2). Kemampuan menerima atas penjelasan delegasi tugas, 3). Peran dan tingkat motivasi seorang pekerja.

\section{Metode Penelitian}

Penelitian ini menggunakan pola eksplanatory yaitu penelitian yang bermaksud menjelaskan kedudukan variabel-variabel yang diteliti serta hubungan antara satu variabel dengan variabel yang lain. Penelitian mengajukan hipotesis : 1). Diduga Motivasi Inrtrinsik berpengaruh terhadap Kinerja Pegawai Kantor Pos Palangka Raya. 2). Diduga Motivasi Ekstrinsik berpengaruh terhadap Kinerja Kantor Pos Palangka Raya. 3). Diduga Lingkungan Kerja berpengaruh terhadap Kinerja Pegawai Kantor Pos Palangka Raya. 4). Diduga Motivasi Intrinsik, Motivasi Ekstrinsik dan Lingkungan Kerja bepengaruh secara simultan terhadap Kinerja Pegawai Kantor Pos Palangka Raya. Variabel yang dianalisis dalam penelitian ini dibedakan menjadi variabel dependen (Y) dan variabel independen (X).

Variabel dependen (Y) adalah variabel tergantung yang keberadaannya dipengaruhi variabel bebas. Dalam penelitian ini variabel dependen adalah kinerja karyawan Pegawai Kantor Pos Palangka Raya. Variabel independen (X) merupakan variabel bebas yang nantinya akan mempengaruhi variabel dependen yang terdiri dari motivasi instrinsik (X1),motivasi ekstrinsik (X2) dan Lingkungan kerja (X3). Berdasarkan dukungan teori dan hasil penelitian terdahulu, maka dapatlah digambarkan kerangka konseptual yang akan digunakan dalam penelitian ini adalah sebagaimana tampak pada gambar dibawah ini:

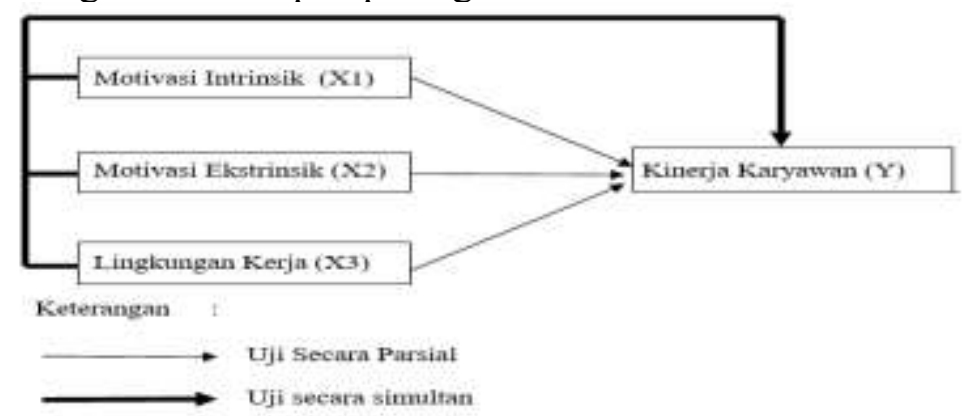

Gambar 1. Kerangka Pikir Penelitian 


\section{Hasil Penelitian}

Suatu variabel dikatakan valid jika memenuhi syarat minimum $r \geq 0,3$ (Sugiono, 2004:115). Kriteria hasil uji validitas terhadap kuesioner menunjukkan bahwa semua item adalah valid. Uji reliabilitas dilakukan dengan tujuan untuk menguji sejauh mana alat pengukur dapat diandalkan. Pengukuran reliabilitas ini dilakukan dengan memakai koefisien Alpha Cronbach ( $\alpha$ ). Biasanya reliabilitas suatu instrumen diterima jika memiliki Alpha Cronbach lebih besar dari 0,5.

Tabel 1. Hasil Uji Reliabilitas Instrumen Penelitian

\begin{tabular}{|c|c|c|}
\hline Variabel & Koefisien & Keterangan \\
\hline $\mathrm{X} 1$ & 0.842 & Reliabel \\
\hline $\mathrm{X} 2$ & 0.657 & Reliabel \\
\hline $\mathrm{X} 3$ & 0.910 & Reliabel \\
\hline $\mathrm{Y}$ & 0.877 & Reliabel \\
\hline
\end{tabular}

Sumber: Data diolah Author, 2020

Secara umum uji linieritas untuk mengetahui apakah dua variabel mempunyai hubungan yang linier secara signifikan atau tidak. Untuk mengetahui apakah variabel $\mathrm{X}$ dengan variabel $\mathrm{Y}$ mempunyai hubungan yang linier atau tidak, dapat diketahui dengan melihat nilai $\mathrm{F}$ hitung dengan $\mathrm{F}$ tabel. Jika $\mathrm{F}$ hitung $>\mathrm{F}$ tabel kesimpulannya adalah tidak terdapat hubungan yang linier dan sebaliknya jika $\mathrm{F}$ hitung $<\mathrm{F}$ tabel kesimpulannya terdapat hubungan yang linier antara variabel X dengan variabel Y. Diketahui F hitung sebesar 26.477> F tabel sebesar 3,23 jadi dapat disimpulkan bahwa tidak terdapat hubungan yang linier antara variabel $\mathrm{X}$ terhadap variable Y. Selanjutnya, Persamaan Regresi Berganda menunjukkan hasil :

Tabel 2. Hasil Persamaan Regresi Linear Berganda Coefficients $^{a}$

\begin{tabular}{|c|c|c|c|c|c|c|}
\hline \multirow{2}{*}{\multicolumn{2}{|c|}{ Model }} & \multicolumn{2}{|c|}{$\begin{array}{c}\text { Unstandardized } \\
\text { Coefficients }\end{array}$} & \multirow{2}{*}{\begin{tabular}{|c|}
$\begin{array}{c}\text { Standardized } \\
\text { Coefficients }\end{array}$ \\
Beta \\
\end{tabular}} & \multirow[b]{2}{*}{$\mathrm{t}$} & \multirow[b]{2}{*}{ Sig. } \\
\hline & & $\mathrm{B}$ & Std. Error & & & \\
\hline \multirow[t]{4}{*}{1} & (Constant) & .110 & .588 & & .187 & .852 \\
\hline & Motivasi intrinsik(X1) & .421 & .146 & .385 & 2.833 & .010 \\
\hline & Motivasi Ekstrinsik(X2) & .531 & .129 & .509 & 4.103 & .000 \\
\hline & Lingkungan Kerja (X3) & .589 & .167 & 424 & 3.530 & .001 \\
\hline
\end{tabular}

a. Dependent Variable: Kinerja Karyawan( $Y)$

Berdasarkan tabel di atas dapat ditentukan model regresi linear berganda yang dinyatakan dalam bentuk persamaan sebagai berikut:

$\mathrm{Y}=0.110+0.421 \mathrm{X} 1+0.531 \mathrm{X} 2+0.589 \mathrm{X} 3+\mathrm{e}$

Dari nilai persamaan regresi diatas dapat diketahui bahwa:

1. Konstanta sebesar 0.110 artinya jika variabel Motivasi Instrinsik, Motivasi Ekstrinsik dan Lingkungan Kerja konstant atau tetap, maka nilai kinerja pegawai adalah 0.110 atau bila dipersentasikan sebesar $11 \%$.

2. Nilai Koefisien Regresi untuk variabel Motivasi Instrinsikpada persamaan regresi menunjukan nilai positif sebesar 0.421 , artinya jika Motivasi Instrinsik meningkat sebesar 1 satuan maka nilai kinerja pegawai akan meningkat 0.421 , dengan kata lain, besarnya pengaruh Motivasi Instrinsikterhadap kinerja pegawai adalah 0.421 atau $42.1 \%$.

3. Nilai Koefisien Regresi untuk variable Motivasi Ekstrinsik pada persamaan regresi menunjukan nilai positif sebesar 0.531 , artinya jika dan Motivasi Ekstrinsikmeningkat 
sebesar 1 satuan maka nilai kinerja pegawai akan meningkat 0.531 dengan kata lain, besarnya pengaruh Motivasi Ekstrinsik terhadap kinerja pegawai adalah 0.531 atau 53,1 $\%$.

4. Nilai Koefisien Regresi untuk variable Lingkungan Kerja pada persamaan regresi menunjukan nilai positif sebesar 0.589 , artinya jika dan Lingkungan Kerja meningkat sebesar 1 satuan maka nilai kinerja pegawai akan meningkat 0.589 dengan kata lain, besarnya pengaruh Lingkungan Kerjaterhadap kinerja pegawai adalah 0.589 atau 58,9 \%.

Berdasarkan data, hasil uji parsial sebagai berikut :

Tabel 3. Hasil Uji Parsial (t)

\begin{tabular}{|ll|r|r|}
\hline & & & \\
& & & \\
Model & & $\mathrm{t}$ & \multicolumn{1}{c|}{ Sig. } \\
\hline 1 & (Constant) & .187 & .852 \\
& Motivasi Intrinsik (X1) & 2.833 & .010 \\
& Motivasi Eksrinsik(X2) & 4.103 & .000 \\
& Lingkungan Kerja & 3.530 & .001 \\
\hline
\end{tabular}

Koefisien dari variabel Motivasi Intrinsik(X1) adalah signifikan pada $\alpha=0,05$, karena $\mathrm{t}$ hitung $>2.833 \mathrm{t}$ tabel $1,699(2.833>1,699)$ atau nilai sig. $0.10<0,05$. Artinya pengaruh variabel Motivasi Intrinsik terhadap kinerja pegawai adalah signifikan. Berarti hipotesis yang menyatakan bahwa Motivasi Intrinsik berpengaruh terhadap kinerja pegawai bisa diterima.

Koefisien dari Motivasi Ekstrinsik (X2) adalah signifikan pada $\alpha=0,05$, karena thitung $4.103>$ t tabel $1.699(4.103>1,699)$ atau nilai sig. $0.000<0,05$. Artinya pengaruh variabel Motivasi Ekstrinsik terhadap kinerja Karyawan adalah signifikan. Berarti hipotesis yang menyatakan bahwa Motivasi Ekstrinsik berpengaruh terhadap kinerja pegawai bisa diterima.

Koefisien dari Lingkungan $\operatorname{Kerja}(X 3)$ adalah signifikan pada $\alpha=0,05$, karena t hitung $3.530>\mathrm{t}$ tabel $1.699(3.530>1,699)$ atau nilai sig. $0.001<0,05$. Artinya pengaruh variabel Lingkungan Kerja terhadap kinerja Karyawan adalah signifikan. Berarti hipotesis yang menyatakan bahwa Lingkungan Kerja berpengaruh terhadap kinerja pegawai bisa diterima. Selanjutnya hasil uji F (simultan), sebagai berikut.

Tabel 4. Hasil Uji Simultan (F)

ANOVA $^{\text {b }}$

\begin{tabular}{|ll|r|r|r|r|r|}
\hline Model & & Sum of Squares & Df & Mean Square & F & Sig. \\
\hline 1 & Regression & 17.793 & 2 & 5.931 & 26.477 & $.000 .^{b}$ \\
& Residual & 9.184 & 41 & .224 & & \\
Total & 26.978 & 44 & & & \\
& & & & & \\
\hline
\end{tabular}

a. Predictors: (Constant), Lingkungan Kerja (X3),Motivasi Ekstrinsik(X2), Motivasi intrinsik , ( X1)

b. Dependent Variable: Kinerja Pegawai $(Y)$

Uji ini digunakan dengan tujuan untuk membuktikan apakah variabel bebas berpengaruh secara bersama-sama terhadap variabel terikat. Dari hasil perhitungan melalui

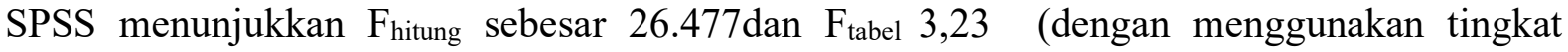
signifikasi $0,00 \%$ serta derajat kebebasan $(\mathrm{df}) ; \mathrm{n}-(\mathrm{k}+1) ; 45-(2+1)=42)$. Ini menyatakan bahwa $f_{\text {hitung }}(26.477)>F_{\text {tabel }}(3,23)$ sehingga hipotesis diterima. Artinya bahwa variabel bebas yang terdiri dari Motivasi Intrinsik (X1),Motivasi Ektrinsik(X2) dan Lingkungan Kerja (X3)secara simultan berpengaruh terhadap Kinerja Pegawai Kantor Pos Palangka Raya. Dari data menunjukkan hasil Koefisien Determinasi $\left(\mathrm{R}^{2}\right)$, sebagai berikut. 
Tabel 5. Koefisien Determinasi $\left(\mathrm{R}^{2}\right)$

Model Summaryb

\begin{tabular}{|l|l|l|l|l|l|}
\hline Model & $R$ & R Square & $\begin{array}{l}\text { Adjusted R } \\
\text { Square }\end{array}$ & $\begin{array}{l}\text { Std. Error of the } \\
\text { Estimate }\end{array}$ & Durbin-Watson \\
\hline 1 & $.812^{\mathrm{a}}$ & .660 & .635 & .47329 & 1.380 \\
\hline
\end{tabular}

a. Predictors: (Constant), Lingkungan Kerja (Y),Motivasi Ekstrinsik (X2), Motivasi intrinsik , ( X1)

b. Dependent Variable: Kinerja Karyawan (Y)

Nilai koefisien determinasi (R2) sebesar 0.660 menunjukkan bahwa variasi kinerja karyawan dijelaskan oleh variabel Motivasi Intrinsik (X1),Motivasi Ektrinsik (X2) dan lingkungan Kerja (X3) sebesar 66.0\% sementara 34.0\% dijelaskan oleh variabel lain yang tidak dianalisis dalam model.

\section{Pembahasan}

Pengaruh variabel Motivasi Intrinsik (X1) terhadap kinerja Pegawai (Y), Berdasarkan hasil analisis secara parsial, diperoleh bahwa koefisien $\beta$ dari Motivasi Intrinsik(X1) adalah positif, tanda positif menunjukkan bahwa hubungan antara variabel Motivasi Intrinsik (X1) dengan variabel Kinerja pegawai (Y) adalah searah, artinya bahwa semakin tinggi Variabel Motivasi Intrinsikseorang pegawai maka akan semakin tinggi pula kinerja yang dimilikinya. Setelah dilakukan pengujian maka ternyata bahwa nilai sig adalah signifikan, dengan demikian berarti bahwa terdapat pengaruh yang signifikan antara Motivasi Intrinsik(X1) terhadap Kinerja pegawai $(\mathrm{Y})$.

Pengaruh Motivasi Ekstrinsik (X2) terhadap kinerja Pegawai (Y). Berdasarkan hasil analisis secara parsial, diperoleh bahwa koefisien $\beta$ dari Motivasi Ekstrinsik(X2) adalah positif, tanda positif menunjukkan bahwa hubungan antara variabel Motivasi Ekstrinsik(X2) dengan variabel Kinerja pegawai (Y) adalah searah, artinya bahwa semakin tinggi Motivasi Ekstrinsikseorang pegawai maka akan semakin tinggi pula kinerja yang dimilikinya. Setelah dilakukan pengujian maka ternyata bahwa nilai sig adalah signifikan, dengan demikian berarti bahwa terdapat pengaruh yang signifikan antara Motivasi Ekstrinsik(X2) terhadap Kinerja pegawai (Y).

Pengaruh Lingkungan Kerja (X3) terhadap kinerja Pegawai (Y). Berdasarkan hasil analisis secara parsial, diperoleh bahwa koefisien $\beta$ dari Lingkungan Kerja (X3)adalah positif, tanda positif menunjukkan bahwa hubungan antara variabel Lingkungan Kerja (X3) dengan variabel Kinerja pegawai (Y) adalah searah, artinya bahwa semakin tinggi Lingkungan Kerja (X3) seorang pegawai maka akan semakin tinggi pula kinerja yang dimilikinya. Setelah dilakukan pengujian maka ternyata bahwa nilai sig adalah signifikan, dengan demikian berarti bahwa terdapat pengaruh yang signifikan antara Lingkungan Kerja (X3) terhadap Kinerja pegawai (Y).

Pengaruh Simultan Variabel Motivasi Intrinsik (X1) dan Motivasi Ekstrinsik (X2) dan Lingkungan Kerja (X3) terhadap kinerja pegawai (Y). Berdasarkan hasil analisis secara simultan, diperoleh bahwa Motivasi Intrinsik (X1) dan Motivasi Ekstrinsik (X2) dan Lingkungan Kerja (X3)adalah positif, tanda positif menunjukkan bahwa hubungan antara variabel Motivasi Intrinsik (X1) dan Motivasi Ekstrinsik (X2) dan Lingkungan Kerja (X3) dengan variabel Kinerja Pegawai (Y) adalah searah, artinya bahwa semakin tinggi Motivasi Intrinsik (X1) dan Motivasi Ekstrinsik (X2) dan Lingkungan Kerja (X3) seorang pegawai maka akan semakin tinggi pula kinerja yang dimilikinya. 


\section{SIMPULAN DAN SARAN}

1. Motivasi Intrinsik (X1) berpengaruh terhadap Kinerja Pegawai Kantor Pos Palangka Raya.

2. Motivasi Ekstrinsik (X2) berpengaruh terhadap Kinerja Pegawai Kantor Pos Palangka Raya.

3. Lingkungan Kerja (X3) berpengaruh Terhadap Kinerja Pegawai Kantor Pos Palangka Raya

4. Motivasi Intrinsik (X1), Motivasi Ekstrinsik (X2) dan Lingkungan Kerja (X3) berpengaruh secara simultan terhadap Kinerja Pegawai Kantor Pos Palangka Raya. Berdasarkan kesimpulan diatas maka dapat dikemukakan beberapa saran-saran sebagai berikut: Bagi pimpinan Kantor Pos Palangka Raya agar lebih memperhatikan variabel Motivasi Intrinsik (X1),Motivasi Ekstrinsik (X2) dan Lingkungan Kerja (X3) agar kinerja dapat ditingkatkan. Indikator-indikator yang sudah ada lebih dicermati dan dikembangkan agar pimpinan dan pegawai dapat mencapai kepuasan secara bersama-sama. Bagi peneliti selanjutnya dapat memanfaatkan dan mengembangkan hasil penelitian ini dengan menggunakan variabelvariabel yang berbeda atau indikator-indikator yang digunakan masing-masing variabel perlu dikembangkan. Penelitian ini masih memiliki keterbatasan, mengingat pada penelitian ini hanya menganalisis bagaimana pengaruh Motivasi Intrinsik (X1), Motivasi Ekstrinsik (X2) dan Lingkungan Kerja (X3) terhadap Kinerja pegawai. Kalau kita melihat berbagai teori yang berkenaan dengan Kinerja pegawai tentunya banyak faktor yang mempengaruhinya. Oleh sebab itu penelitian ini dapat lebih disempurnakan dan dikembangkan dengan menambah berbagai variabel lainnya, sehingga penelitian ini lebih bermanfaat bagi pengembangan ilmu pengetahuan dan kepentingan dunia praktis.

\section{Referensi}

Akbar, F. N. (2012). Pengaruh Motivasi Intrinsik dan Motivasi Ekstrinsik Terhadap Kinerja Karyawan Pada PT Perkebunan Nusantara XII Surabaya. Jurnal Ilmiah Mahasiswa $F E B, 1(2)$.

Amstrong, M dan Baron, A. (2007). A handbook of human resource management practice. (9th). London: Kogan Page

Arikunto, S. (2013). Prosedur Penelitian Suatu Pendekatan Praktik. Edisi Revisi. Jakarta: PT. Rineka Cipta.

Bahrul Kirom (2010). Mengukur Kinerja Pelayanan dan Kepuasan. Konsumen. Bandung : Pustaka Reka Cipta.

Danang, Sunyoto. (2012). Manajemen Sumber Daya Manusia. Jakarta: PT Buku ... Ebook.

Fauzan. (2001). Pengaruh Motivasi Internal dan Motivasi Eksternal Terhadap Prestasi Kerja Karyawan Bank Pembangunan Kalteng. Skripsi Fakultas EKonomi dan Bisnis Universitas palangka Raya.

Ghozali, Imam. (2011). Analisis Multivariat Dengan Program SPSS. Semarang: Badan Penerbit Universitas Diponegoro.

Gibson. (2013). Penilaian Kinerja. Jakarta: Penerbit Erlangga.

Handoko, T. Hani. (2014). Manajemen Personalia dan Sumber Daya Manusia. Yogyakarta: BPFE.

Hasibuan, Malayu S.P. (2016). Manajemen Sumber Daya Manusia. Edisi Revisi. Jakarta: Penerbit PT Bumi Aksara.

Luthans, Fred. (2006). Organizational Behavior. Nineth Edition. Singapore: McGraw Hill.

Mangkunegara, Anwar Prabu. (2005). Perilaku dan Budaya Organisasional. Bandung: PT. 
Refika Aditama.

Martina. B. (2015). Pengaruh Motivasi dan Lingkungan Kerja terhadap kinerja Karyawan Pada PT. Atri Distributor. Skripsi Fakultas EKonomi dan Bisnis Universitas palangka Raya

Marwansyah, M. (2016). Manajemen sumber daya manusia. Edisi II. Politeknik Negeri Bandung.

Masluk Han, F. (2015). Pengaruh Budaya Organisasi Terhadap Kinerja Karyawan (Studi Kasus Pada Rumah Sakit Yarsis Surakarta). Doctoral dissertation, Universitas Muhammadiyah Surakarta.

Mathis, Robert L dan John H. Jackson. (2012). Manajemen Sumber Daya Manusia. Buku 1. Alih Bahasa: Jimmy Sadeli dan Bayu. Prawira Hie. Jakarta: Salemba Empat.

Maulana, F. H. (2015). Pengaruh motivasi intrinsik, motivasi ekstrinsik dan komitmen organsasi terhadap kinerja karyawan pada Bank BTN Kantor Cabang Malang. Jurnal Administrasi Bisnis, 22(1).

Nawawi, Hadari. (2001). Manajemen Sumber Daya Manusia untuk Bisnis yang Kompetitif. Cetakan Keempat. Yogyakarta: Penerbit Gadjah Mada University Press.

Nitisemito. (2013). Manajemen Personalia (Manajemen Sumber Daya. Manusia). Cetakan VIII. Jakarta: Ghalia Indonesia.

Robbins, Coultur. (2010). Prinsip-prinsip Perilaku Organisasi. Edisi Lima. Jakarta: Penerbit Erlangga.

Robbins, P. Stephen \& Coutler, Mary. (2016). Human Resources Management. Edisi 16. Jilid 1. Jakarta: Salemba Empat, Jakarta.

Robbins, Stephen P \& Judge. (2013). Organizational Behavior. 15 th Edition. New Jersey: Pearson Education.

Sedarmayanti. (2011). Tata Kerja dan Produktivitas Kerja Suatu Tinjauan dari Aspek Ergonomi atau Kaitan antara Manusia dengan Lingkungan Kerja. Bandung: CV. Mandar Maju.

Sekaran, Uma. 2011. Research Methods For Business. Buku 1 dan 2 edisi 4. Jakarta: Salemba Empat.

Siagian, S.P. (2013). Manajemen Sumber Daya Manusia (Human Resources Management) Suatu Pendekatan Mikro. Cetakan Kedua. Jakarta: Penerbit Djambatan.

Siagian, S.P. (2013). Manajemen Sumber Daya Manusia. Jakarta: Bumi Aksara

Simamora, Henry. (2002). Manajemen Sumber Daya Manusia Edisi Ketiga Cetakan Pertama. Yogyakarta: Penerbit STIE YKPN.

Sofyandi, Herman. (2013). Manajemen Sumber Daya Manusia. Cetakan kedua. Yogyakarta: Graha ilmu.

Sugiyono. (2016). Metode Penelitian Kuantitatif, Kualitatif dan R\&D. Bandung: PT Alfabet.

Sukwandani, Radyanti Paramitha. (2007). Pengaruh Motivasi Ekstrinsik, Motivasi Ekstrinsik dan Budaya Perusahaan Terhadap Kinerja Karyawan (Study Pada PG. Rejo Agung Baru, Madiun).

Suprihanto, J., Harsiwi, A. M., \& Hadi, P. (2003). Perilaku organisasional. Yogyakarta: STIE KPN. 
Suwatno.\&Priansa, D. (2011). Manajemen SDM dalam Organisasi Publik dan Bisnis. Bandung: Alfabeta.

Swasto, Bambang. (2011). Manajemen Sumber Daya Manusia. Malang: UB Press. Bohlander.

Teo,Thompson. (2001). Demografic And Motivation Variables Associated With Internet Usage Activities. Internet Research Electronic Networking Applications And Policy.

Vroom, V. H. \& Deci, E. L. (2001). Manajement and Motivation. Penguin Education.

Wibowo, Fajar. (2016). Pengaruh Lingkungan Kerja, Motivasi Intrinsik dan Motivasi Ekstrinsik terhadap kinerja karyawan ( Studi pada Graha Optimasi Triasindo Denpasar). Skripsi Fakultas EKonomi dan Bisnis Universitas palangka Raya.

Wibowo. (2011). Manajemen Kinerja. Jakarta: Raja Grafindo Persada.

Winardi, J. (2001). Motivasi dan Pemotivasian dalam Manajemen. Jakarta: Raja Grafindo Persada 